OPEN ACCESS

Edited by:

Jirong Huang,

University of Tokyo, Japan

Reviewed by:

Stefano Santabarbara,

Consiglio Nazionale delle

Ricerche, Italy

Lianwei Peng,

Institute of Botany, The Chinese

Academy of Sciences, China

*Correspondence:

Wei Huang

Key Laboratory of Tropical Forest

Ecology, Xishuangbanna Tropical

Botanical Garden, Chinese Academy

of Sciences, Menglun, Mengla

666303, Yunnan, China

huangwei@mail.kib.ac.cn;

Hong $\mathrm{Hu}$,

Key Laboratory of Economic Plants and Biotechnology, Kunming Institute of Botany, Chinese Academy

of Sciences, 132\# Lanhei Road, Heilongtan, Kunming 650201,

Yunnan, China

huhong@mail.kib.ac.cn

Specialty section: This article was submitted to Plant Physiology,

a section of the journal

Frontiers in Plant Science

Received: 25 June 2015 Accepted: 14 September 2015 Published: 29 September 2015

Citation:

Huang W, Zhang S-B, Zhang J-L and $\mathrm{Hu} H$ (2015) Photoinhibition of photosystem I under high light in the shade-established tropical tree

species Psychotria rubra.

Front. Plant Sci. 6:801.

doi: 10.3389/fp/s.2015.00801

\section{Photoinhibition of photosystem I under high light in the shade-established tropical tree species Psychotria rubra}

\author{
Wei Huang ${ }^{1,2 *}$, Shi-Bao Zhang ${ }^{2}$, Jiao-Lin Zhang ${ }^{1}$ and Hong Hu ${ }^{2 *}$ \\ ${ }^{1}$ Key Laboratory of Tropical Forest Ecology, Xishuangbanna Tropical Botanical Garden, Chinese Academy of Sciences, \\ Mengla, China ${ }^{2}$ Key Laboratory of Economic Plants and Biotechnology, Kunming Institute of Botany, Chinese Academy \\ of Sciences, Kunming, China
}

The photosynthetic sensitivity to high light differs among understory plants of shade- and sun- established tree species. Shade-established tree species are sensitive to high light but the underlying photosynthetic mechanism has not been fully resolved. In the present study, we examined the responses of photosystem I (PSI) and photosystem II (PSII) to high light in shade leaves of a shade-established tree species Psychotria rubra and a sun-established tree species Pometia tomentosa. After exposure to $2000 \mu \mathrm{mol}$ photons $\mathrm{m}^{-2} \mathrm{~s}^{-1}$ for $2 \mathrm{~h}$, the maximum photo-oxidizable P700 $\left(P_{m}\right)$ decreased by 40 and $9 \%$ in $P$. rubra and $P$. tomentosa, respectively. These results indicate that the shade-established species $P$. rubra is incapable of protecting PSI under high light. Strong photoinhibition of PSII under high light led to large depression of electron transfer from PSII to PSI and then prevented further photodamage to PSI. During the high light treatment of $2000 \mu \mathrm{mol}$ photons $\mathrm{m}^{-2} \mathrm{~s}^{-1}$, PSI photoinhibition in P. rubra was accompanied with high levels of cyclic electron flow (CEF) and P700 oxidation ratio. Therefore, we propose that PSI photoinhibition under high light in $P$. rubra is dependent on electron transfer from PSII to $\mathrm{PSI}$, and CEF is unlikely to play a major role in photoprotection for PSI in P. rubra. These findings suggest that photoinhibition of PSI is another important mechanism underlying why shade-established species cannot survive under high light.

Keywords: cyclic electron flow, high light, photoinhibition, photosystem I, shade-established species

\section{Introduction}

Under high light condition, excess absorbed light energy can induce photoinhibition (Powles, 1984; Barber and Andersson, 1992; Aro et al., 1993a,b; Takahashi et al., 2009; Takahashi and Badger, 2011), especially in shade leaves (Aro et al., 1993b; Kitao et al., 2000; Barth et al., 2001; Krause et al., 2004). In the understory of tropical rain forests, leaves grown in light condition of deep shade $(<5 \%$ of full sunlight). When canopy gaps are created by tree fall, shade leaves may be exposed to direct sunlight for several hours in a day. High light induced a large decrease in PSII activity in shade leaves of pioneer and late-succession tree species (Kitao et al., 2000; Barth et al., 2001; Krause et al., 2004), while photosystem I (PSI) activity was usually unaffected in these shade leaves (Barth et al., 2001). However, it is unclear whether PSI activity is susceptible to high light in shade-established tree species. 
Previous studies have indicated that PSI photoinhibition mainly occurs in chilling-sensitive species including cucumber and Arabidopsis thaliana when exposed to chilling-light stress (Havaux and Davaud, 1994; Terashima et al., 1994; Sonoike, 1995; Barth and Krause, 1999; Zhang and Scheller, 2004). Photoinhibition of PSI is mainly caused by the oxidation of hydroxyl radicals that are generated by a reaction between reduced iron-sulfur centers and hydroxyl peroxide (Sonoike, 1995, 2011). Therefore, over-reduction of PSI acceptor side and production of hydroxyl peroxide are the two main causes of PSI photoinhibition (Sonoike et al., 1997; Munekage et al., 2002). Plants have several mechanisms to protect PSI against photoinhibition, such as antioxidative scavenging system (Hwang et al., 2004) and cyclic electron flow (CEF; Munekage et al., 2002). CEF can protect PSI activity by increasing the P700 oxidation ratio (Munekage et al., 2002, 2004). P700 ${ }^{+}$can harmlessly dissipate excess light energy as heat and protect PSI activity (Nuijs et al., 1986). Although wild type of Arabidopsis thaliana and cucumber have CEF activity (Kim et al., 2001; Munekage et al., 2004), they display PSI photoinhibition when illuminated at chilling temperature (Terashima et al., 1994; Kudoh and Sonoike, 2002; Zhang and Scheller, 2004). These results suggest that PSI photoinhibition cannot be wholly prevented by the activation of CEF under extreme environmental stresses. Since high light can cause an over-reduction of photosynthetic electron transport chain and production of a large amount of hydroxyl peroxide in the acceptor side of PSI (Murata et al., 2007), it is speculated that high light can lead to PSI photoinhibition in leaves of shade-established tree species.

It has been shown that PSII activity can be quickly repaired under low light in several hours due to the fast turnover of D1 protein (Aro et al., 1993a,b; Allakhverdiev and Murata, 2004; Murata et al., 2007). In contrast to PSII activity, the recovery of PSI activity from photoinhibition is a slow process that needs several days (Kudoh and Sonoike, 2002; Zhang and Scheller, 2004). The fast recovery of PSII activity under low light is dependent on moderate PSI activity (Kudoh and Sonoike, 2002; Huang et al., 2010a,b; Tikkanen et al., 2010). Severe PSI photoinhibition depressed the rate of PSII repair or caused the failing of PSII recovery (Kudoh and Sonoike, 2002; Huang et al., 2010a). Since PSI complex involves in the activation of CEF (Peng and Shikanai, 2011), an irreversible PSI photoinhibition lead to a depression of CEF activity (Huang et al., 2013). The activation of CEF on condition of excess light energy is essential for PSII activity, impairment of CEF activity not only aggravated the rate of photodamage to PSII (Takahashi et al., 2009), but also increased the production of reactive oxygen species that inhibit the synthesis of D1 protein (Nishiyama et al., 2001, 2004, 2005, 2006, 2011; Takahashi et al., 2009). Thus, severe PSI photoinhibition can finally cause the failure of PSII recovery and finally the death of the plant (Huang et al., 2010a; Tikkanen et al., 2010). We speculate that the susceptibility to high light in leaves of shade-established tree species may be partly due to PSI photoinhibition.

In our present study, we examined the effect of high light on PSI and PSII activities in shade leaves of two tropical tree species Psychotria rubra (shade-established) and Pometia tomentosa (sun-established). Furthermore, the changes in P700 oxidation ratio and electron flow through PSII and PSI were determined during high light treatments. The following question was addressed: is PSI susceptible to high light in leaves of the shade-established species $P$. rubra?

\section{Materials and Methods}

\section{Plant Materials and Growth Conditions}

Two tropical tree species, Psychotria rubra (Lour.) Poir. (Rubiaceae) and Pometia tomentosa (Blume) Teijsm. \& Binn (Sapindaceae) were studied in our present study. P. rubra is a shade-established shrub species of rain forests native to south of China, Indonesia, Vietnam, Laos, and Malaysia. Pometia tomentosa is a sun-established tree species and plants of this species can reach $45 \mathrm{~m}$ height. $P$. tomentosa is a dominant canopy species of tropical rain forests native to Sri Lanka, Indonesia, and southern Yunnan, China. They grown naturally in tropical rain forest in Xishuangbanna tropical botanical garden $\left(21^{\circ} 54^{\prime} \mathrm{N}\right.$, $101^{\circ} 46^{\prime} \mathrm{E}$ ) that is located in the northern boundary of tropical zone. Mature leaves of shade plants for both species grown at an understory environment with deep shade (light intensity $<5 \%$ of sunlight) were used for photosynthetic measurements.

\section{PSI and PSII Measurements}

The PSI and PSII parameters were measured simultaneously by Dual-PAM-100 (Heinz Walz GmbH, Effeltrich, Germany) as described in Huang et al. (2010a,b) and Suorsa et al. (2012). After high light treatment at 1000 or $2000 \mu$ mol photons $\mathrm{m}^{-2} \mathrm{~s}^{-1}, \mathrm{Y}(\mathrm{I})$, $\mathrm{Y}(\mathrm{II})$, and $\mathrm{Y}(\mathrm{ND})$ were measured after $3 \mathrm{~min}$ adaptation at 1033 or $1953 \mu \mathrm{mol}$ photons $\mathrm{m}^{-2} \mathrm{~s}^{-1}$, respectively. During recovery at $100 \mu \mathrm{mol}$ photons $\mathrm{m}^{-2} \mathrm{~s}^{-1}, \mathrm{Y}(\mathrm{I}), \mathrm{Y}(\mathrm{II})$, and $\mathrm{Y}(\mathrm{ND})$ were measured after $3 \mathrm{~min}$ adaptation at $100 \mu \mathrm{mol}$ photons $\mathrm{m}^{-2} \mathrm{~s}^{-1}$. All photosynthetic measurements were conducted at $25^{\circ} \mathrm{C}$.

In our present study, the maximum chlorophyll fluorescence after dark adaptation $\left(F_{m}\right)$ and maximum quantum yield of PSII $\left[F_{v} / F_{m}=\left(F_{m}-F_{o}\right) / F_{m}\right]$ were measured to estimate the PSII activity, this method has been used widely in previous studies (Suorsa et al., 2012; Huang et al., 2013; Tikkanen et al., 2014). $F_{o}$ was measured after 20 min dark adaptation without saturating pulse (Huang et al., 2013, 2015). $F_{m}$ was measured after 20 min dark adaptation upon illumination of a pulse $(300 \mathrm{~ms})$ of saturating light $\left(10,000 \mu \mathrm{mol}\right.$ photons $\left.\mathrm{m}^{-2} \mathrm{~s}^{-1}\right)$. The effective quantum yield of PSII was calculated as $\mathrm{Y}(\mathrm{II})=\left(F_{m}{ }^{\prime}-F_{s}\right) / F_{m}{ }^{\prime}$ (Genty et al., 1989), where $F_{m}{ }^{\prime}$ is the maximum fluorescence after light adaptation and measured upon illumination of a saturating pulse $\left(300 \mathrm{~ms}\right.$ and $10,000 \mu \mathrm{mol}$ photons $\left.\mathrm{m}^{-2} \mathrm{~s}^{-1}\right), F_{s}$ is the steady-state fluorescence after light adaptation. The maximum photo-oxidizable P700 $\left(P_{m}\right)$ was recorded to estimate the amount of photo-oxidizable PSI centers (Huang et al., 2010a,b, 2013; Suorsa et al., 2012; Tikkanen et al., 2014). In our present study, $P_{m}$ was measured after $20 \mathrm{~min}$ dark adaptation. The $\mathrm{P} 700^{+}$signals $(P)$ may vary between a minimal (P700 fully reduced) and a maximal level (P700 fully oxidized). The maximum level $\left(P_{m}\right)$ was determined with application of a saturation pulse $(300 \mathrm{~ms}$ and $10,000 \mu \mathrm{mol}$ photons $\mathrm{m}^{-2} \mathrm{~s}^{-1}$ ) after pre-illumination with far-red light. $P_{m}{ }^{\prime}$ was determined similar to $P_{m}$ but with actinic 
light instead of far-red light. The quantum yield of PSI was calculated as $\mathrm{Y}(\mathrm{I})=\left(P_{m}{ }^{\prime}-P\right) / P_{m}$, and the $\mathrm{P} 700$ oxidation ratio was calculated as $\mathrm{Y}(\mathrm{ND})=P / P_{m}$ (Huang et al., 2013, 2015; Tikkanen et al., 2014). The electron flow from PSII to PSI was estimated by ETR II $=\mathrm{Y}(\mathrm{II}) \times \mathrm{PPFD} \times 0.5 \times$ abs I, where 0.5 is the proportion of absorbed light reaching PSI or PSII, and abs I is absorbed irradiance taken as 0.85 of incident irradiance. The electron flow through PSI was estimated by ETR $\mathrm{I}=\mathrm{Y}(\mathrm{I}) \times \mathrm{PPFD} \times 0.5 \times 0.85$. Because we did not measure the accurate leaf absorbance and the proportion of absorbed light reaching PSI or PSII in a cross-sectioned leaf, the estimated ETRI and ETRII were not the absolute ETRI and ETRII.

To measure the light response changes in ETRI, ETRII, intact mature leaves were light adapted at a high light $(1033 \mu \mathrm{mol}$ photons $\mathrm{m}^{-2} \mathrm{~s}^{-1}$ ) for $15 \mathrm{~min}$. Afterward, photosynthetic parameters were evaluated at 2-min intervals at photosynthetic photon flux densities (PPFDs) of 1957, 1599, 1292, 830, 536, 344, $221,100,42$, and $11 \mu \mathrm{mol}$ photons $\mathrm{m}^{-2} \mathrm{~s}^{-1}$.

\section{Photoinhibitory Treatments and Subsequent Recovery}

To determine the response of PSI and PSII to high light, detached leaves of both species were exposed to 1000 or $2000 \mu$ mol photons $\mathrm{m}^{-2} \mathrm{~s}^{-1}$ at $25^{\circ} \mathrm{C}$ for $5 \mathrm{~h}$. After exposure to 1000 or $2000 \mu \mathrm{mol}$ photons $\mathrm{m}^{-2} \mathrm{~s}^{-1}$ for $2 \mathrm{~h}$, leaves were illuminated at a low light of $100 \mu$ mol photons $\mathrm{m}^{-2} \mathrm{~s}^{-1}$ for recovery.

\section{Statistical Analysis}

The results were displayed as mean values of six independent experiments. The data were subjected to analysis of variance (ANOVA) using the SPSS 16.0 statistical software. Tukey's multiple comparison test was used at $\alpha=0.05$ significance level to determine whether significant differences exist among different treatments.

\section{Results}

Light response curves indicated that ETRI was largely higher than ETRII in both species when illuminated at light intensities above $344 \mu \mathrm{mol}$ photons $\mathrm{m}^{-2} \mathrm{~s}^{-1}$ (Figures 1A,B). The ETRI/ETRII ratio under high light was much higher than that under low light in both species (Figures 1A,B). For example, at $11 \mu \mathrm{mol}$ photons $\mathrm{m}^{-2} \mathrm{~s}^{-1}$, ETRI/ETRII ratio was 0.72 and 0.83 in $P$. rubra and $P$. tomentosa, respectively. At $1957 \mu \mathrm{mol}$ photons $\mathrm{m}^{-2} \mathrm{~s}^{-1}$, ETRI/ETRII ratio was 2.0 and 1.8 in P. rubra and P. tomentosa, respectively. Because the activation of CEF leads to the increase in ETRI/ETRII ratio (Yamori et al., 2011; Kono et al., 2014; Huang et al., 2015), our results suggested that both species showed highly activation of CEF under high light.

In order to examine the effect of high light on PSI and PSII in both species, detached leaves of $P$. rubra and $P$. tomentosa were exposed to light intensities of 1000 or $2000 \mu \mathrm{mol}$ photons $\mathrm{m}^{-2} \mathrm{~s}^{-1}$. After exposure to $1000 \mu \mathrm{mol}$ photons $\mathrm{m}^{-2} \mathrm{~s}^{-1}$ for $3 \mathrm{~h}, F_{m}$ decreased by 82 and $70 \%$ in $P$. rubra and P. tomentosa, respectively (Figure 2A). Meanwhile, $P_{m}$ decreased by 18 and $4 \%$ in $P$. rubra and $P$. tomentosa, respectively (Figure 2B). When treated at $2000 \mu \mathrm{mol}$ photons $\mathrm{m}^{-2} \mathrm{~s}^{-1}$ for $2 \mathrm{~h}, P_{m}$ decreased
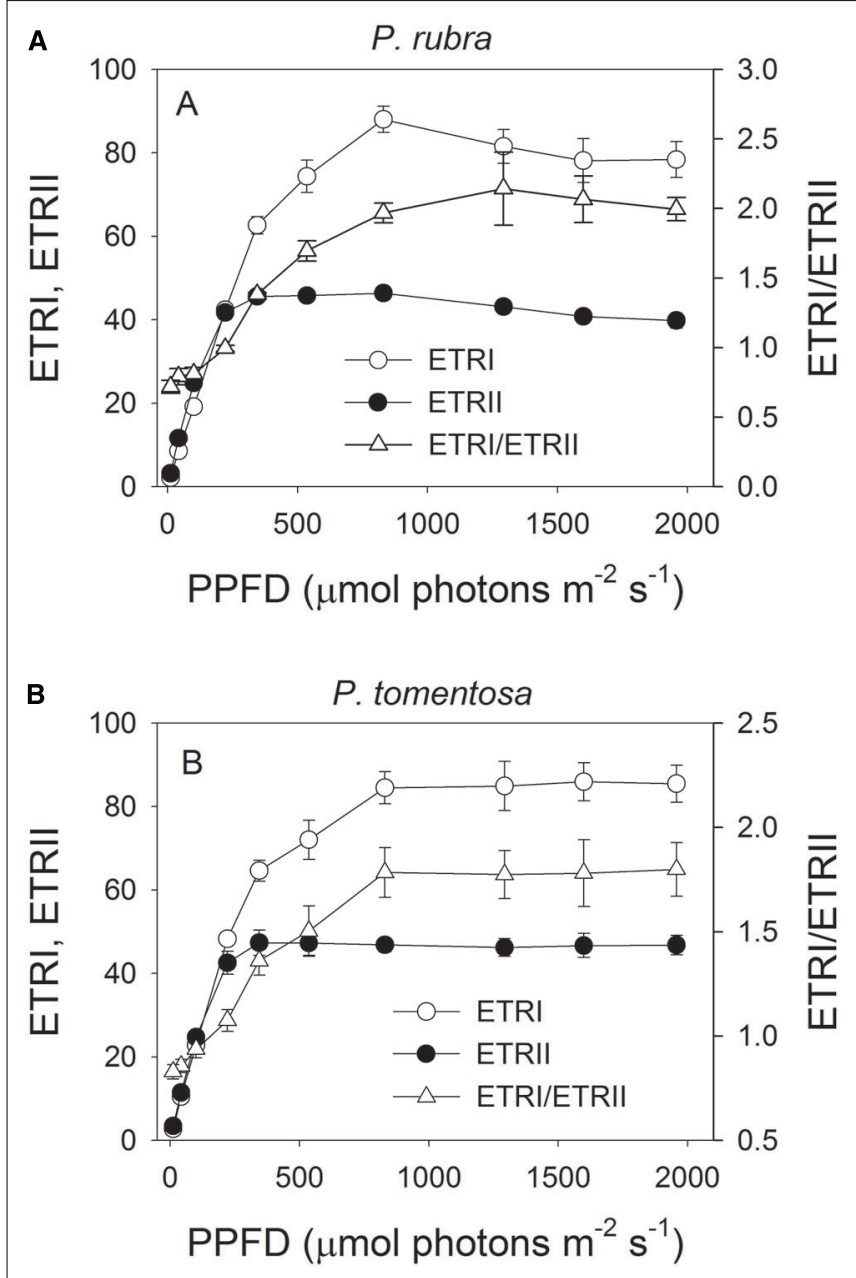

FIGURE 1 | Light response changes in photosynthetic electron flow through PSI and PSII (ETRI and ETRII), and ETRI/ETRII ratio in leaves of Psychotria rubra (A) and Pometia tomentosa (B) measured at $25^{\circ} \mathrm{C}$. The means \pm SE were calculated from six independent plants. The effect of light intensity on the ETRI/ETRII ratio was analyzed by one-way ANOVA. Statistical analysis results indicated that cyclic electron flow was significantly activated under high light in both species $(P<0.05$, One-way ANOVA).

by 40 and $10 \%$ in $P$. rubra and $P$. tomentosa, respectively, and $F_{m}$ decreased by $88 \%$ ( $P$. rubra) and $83 \%$ (P. tomentosa; Figures 2C,D). These results indicated the shade-established species $P$. rubra showed higher sensitivity to PSI photoinhibition under high light. The susceptibility of PSI activity to high light in $P$. rubra was dependent on the intensity of illumination. Interestingly, after exposure to $1000 \mu \mathrm{mol}$ photons $\mathrm{m}^{-2} \mathrm{~s}^{-1}$ for $3 \mathrm{~h}$ or $2000 \mu \mathrm{mol}$ photons $\mathrm{m}^{-2} \mathrm{~s}^{-1}$ for $2 \mathrm{~h}$, PSI activity decreased very slightly during further high light treatment in $P$. rubra (Figures 2B,D).

After high light treatment at 1000 or $2000 \mu$ mol photons $\mathrm{m}^{-2} \mathrm{~s}^{-1}$, the detached leaves of both species were illuminated at $100 \mu \mathrm{mol}$ photons $\mathrm{m}^{-2} \mathrm{~s}^{-1}$ for recovery. The value of $P_{m}$ changed slightly during the recovery process in P. rubra (Figures 3B and 4B), which further confirmed the high-light-induced PSI photoinhibition. For the sun-established species P. tomentosa, 

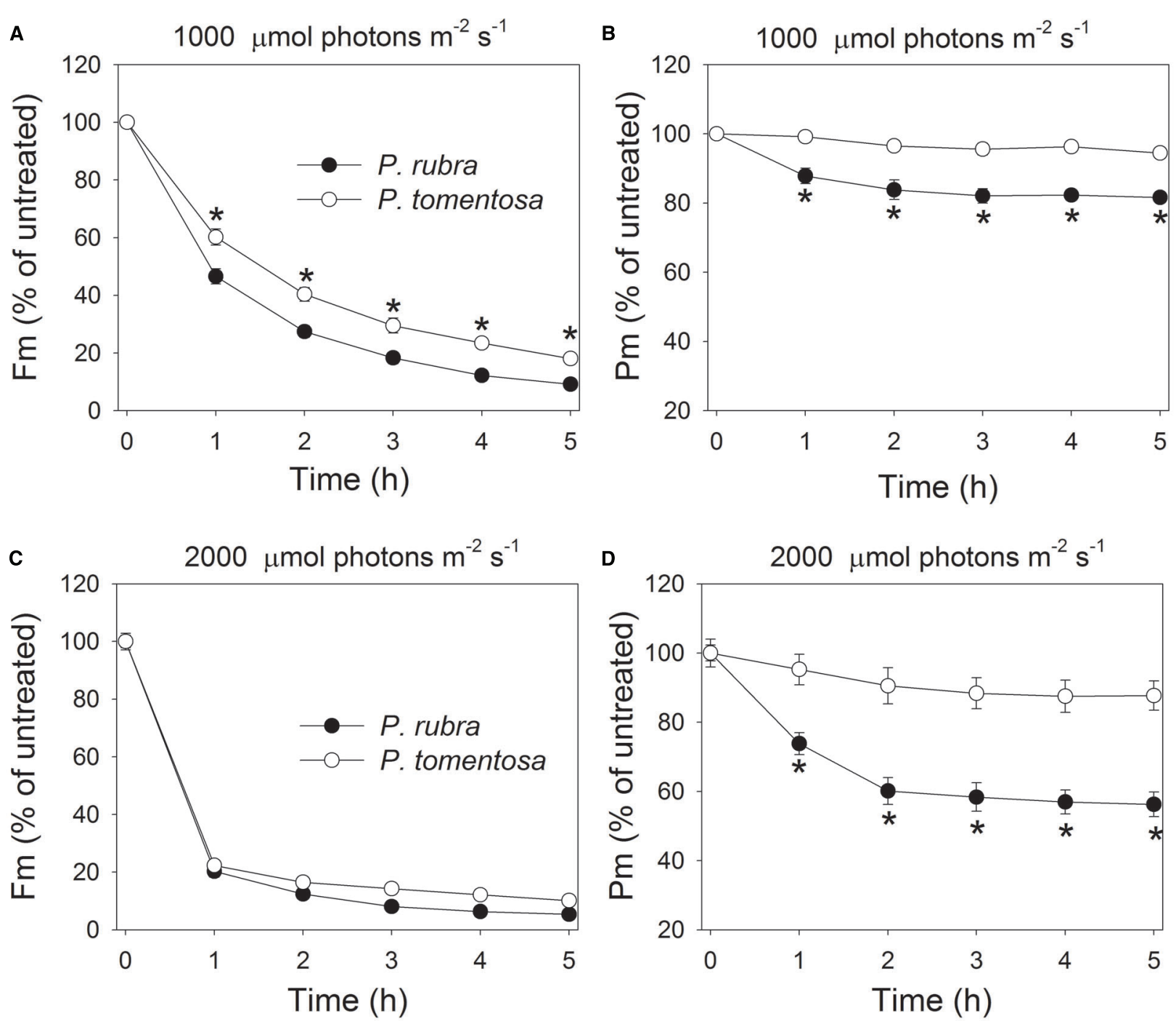

FIGURE $2 \mid$ Changes in $\boldsymbol{F}_{m}(\mathrm{~A}, \mathrm{C})$ and $\boldsymbol{P}_{m}(\mathrm{~B}, \mathrm{D})$ in Psychotria rubra and Pometia tomentosa during treatments at $25^{\circ} \mathrm{C}$ associated with high light intensities of $\mathbf{1 0 0 0}(\mathbf{A}, \mathbf{B})$ and $\mathbf{2 0 0 0}(\mathbf{C}, \mathbf{D}) \mu \mathbf{m o l}$ photons $\mathbf{m}^{-\mathbf{2}} \mathbf{s}^{-\mathbf{1}}$. The means \pm SE were calculated from six independent plants. Asterisks indicate significant differences between Psychotria rubra and Pometia tomentosa.

PSI was insusceptible to high light. $F_{m}$ increased slowly during recovery at $100 \mu \mathrm{mol}$ photons $\mathrm{m}^{-2} \mathrm{~s}^{-1}$ (Figures $3 \mathrm{~A}$ and $4 \mathrm{~A}$ ).

With increasing time of illumination at 1000 or $2000 \mu \mathrm{mol}$ photons $\mathrm{m}^{-2} \mathrm{~s}^{-1}$, PSII photoinhibition gradually increased, and ETRII gradually decreased in both species. After treatment with $1000 \mu \mathrm{mol}$ photons $\mathrm{m}^{-2} \mathrm{~s}^{-1}$ for $3 \mathrm{~h}$, ETRII decreased by $75 \%$ in P. rubra (from 46.9 to $11.6 \mu \mathrm{mol}$ electrons $\mathrm{m}^{-2} \mathrm{~s}^{-1}$ ), and by $52 \%$ in $P$. tomentosa (from 46.0 to $22.2 \mu \mathrm{mol}$ electrons $\mathrm{m}^{-2} \mathrm{~s}^{-1}$ ) (Figures 3C,D). After treatment with $2000 \mu \mathrm{mol}$ photons $\mathrm{m}^{-2}$ $\mathrm{s}^{-1}$ for $2 \mathrm{~h}$, ETRII decreased by 80 and $82 \%$ in $P$. rubra, and $P$. tomentosa, respectively (Figures $4 \mathbf{C}, \mathbf{D}$ ). These results suggested that high levels of PSII photoinhibition depressed electron transfer from PSII to PSI. During the high light treatment, ETRII decreased faster than ETRI in both species (Figures 3C,D and 4C,D). As a result, the values for ETRI-ETRII and ETRI/ETRII increased during high light treatment. Furthermore, the P700 oxidation ratio was maintained at high levels during high light treatment in both species, as shown by the data of Y(ND; Figures 3E,F and 4E,F). These results indicated that CEF was highly activated during exposure to 1000 or $2000 \mu \mathrm{mol}$ photons $\mathrm{m}^{-2} \mathrm{~s}^{-1}$ in both species.

During recovery at $100 \mu \mathrm{mol}$ photons $\mathrm{m}^{-2} \mathrm{~s}^{-1}$, ETRI changed slightly compared with the original values in both species, but ETRII largely declined. After treatment at $1000 \mu \mathrm{mol}$ photons $\mathrm{m}^{-2} \mathrm{~s}^{-1}$ for $3 \mathrm{~h}$, values for ETRII at $100 \mu \mathrm{mol}$ photons $\mathrm{m}^{-2}$ $\mathrm{s}^{-1}$ decreased to 30 and $52 \%$ of the original values in $P$. rubra and $P$. tomentosa, respectively (Figures 3C,D). After exposure to $2000 \mu \mathrm{mol}$ photons $\mathrm{m}^{-2} \mathrm{~s}^{-1}$ for $2 \mathrm{~h}$, values for ETRII during recovery were approximately 17 and $46 \%$ of the original values in $P$. rubra and $P$. tomentosa, respectively (Figures 4C,D). Meanwhile, the value of $\mathrm{Y}(\mathrm{ND})$ at $100 \mu \mathrm{mol}$ photons $\mathrm{m}^{-2} \mathrm{~s}^{-1}$ largely increased during the recovery compared the original values 


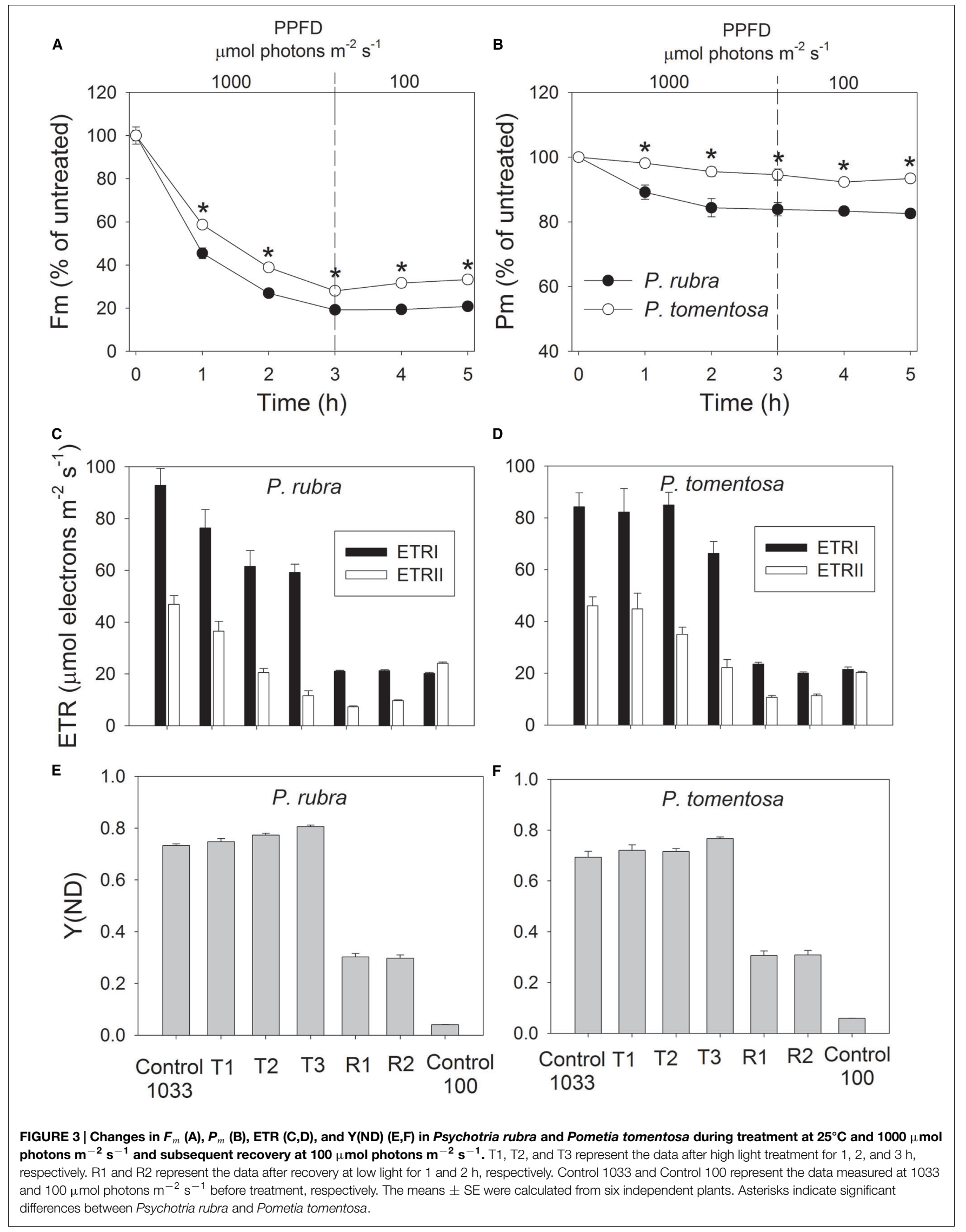



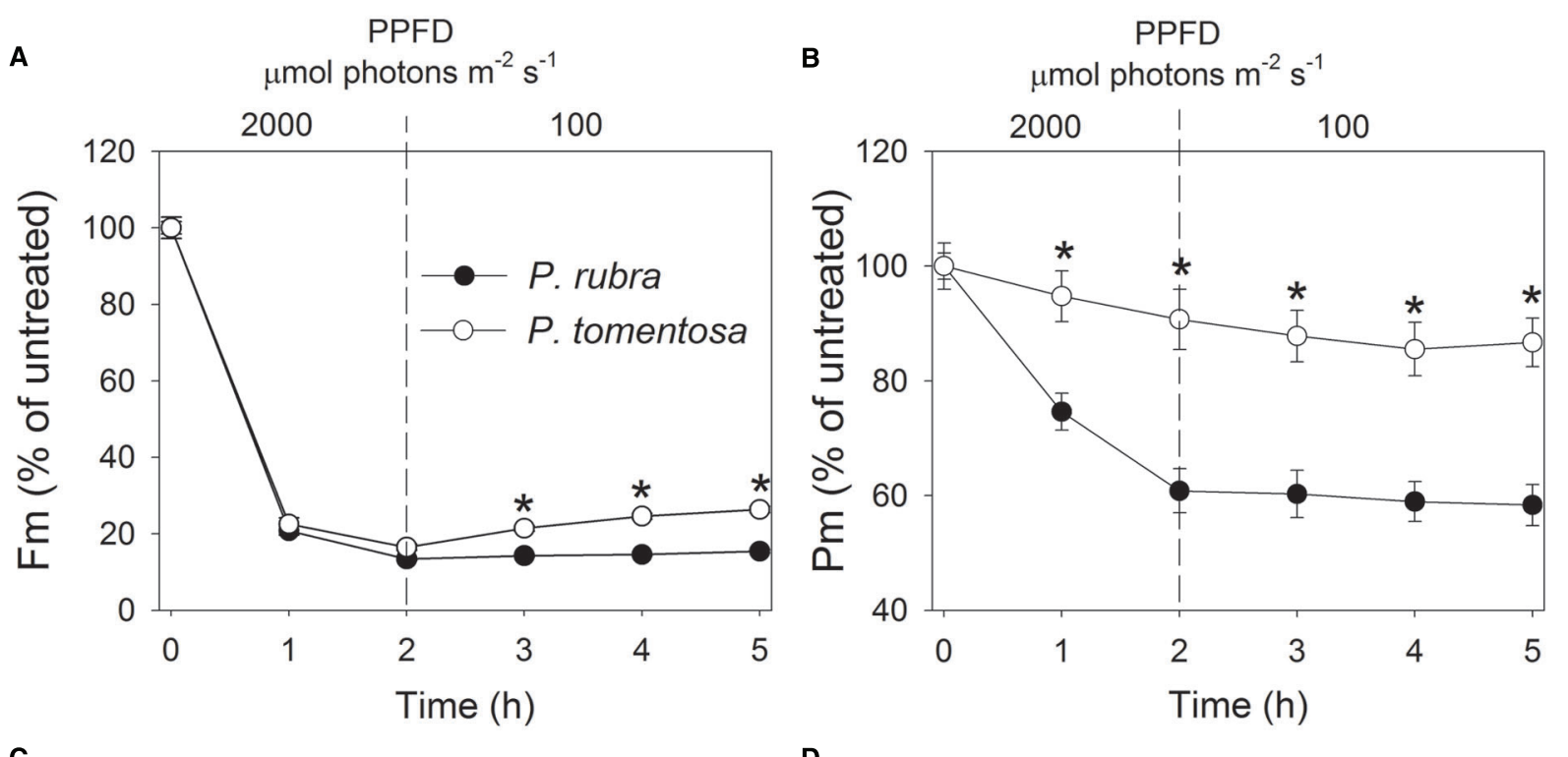

B $\quad \mu \mathrm{mol}$ photons $\mathrm{m}^{-2} \mathrm{~s}^{-1}$

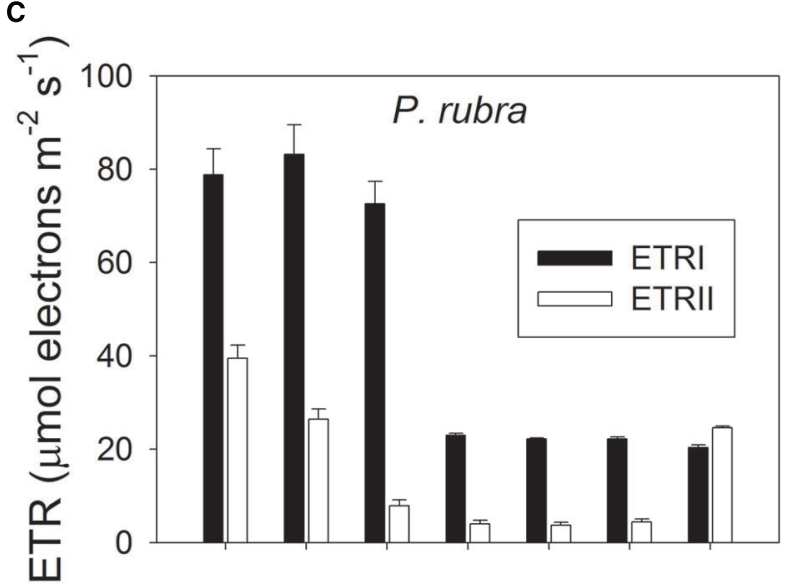

D
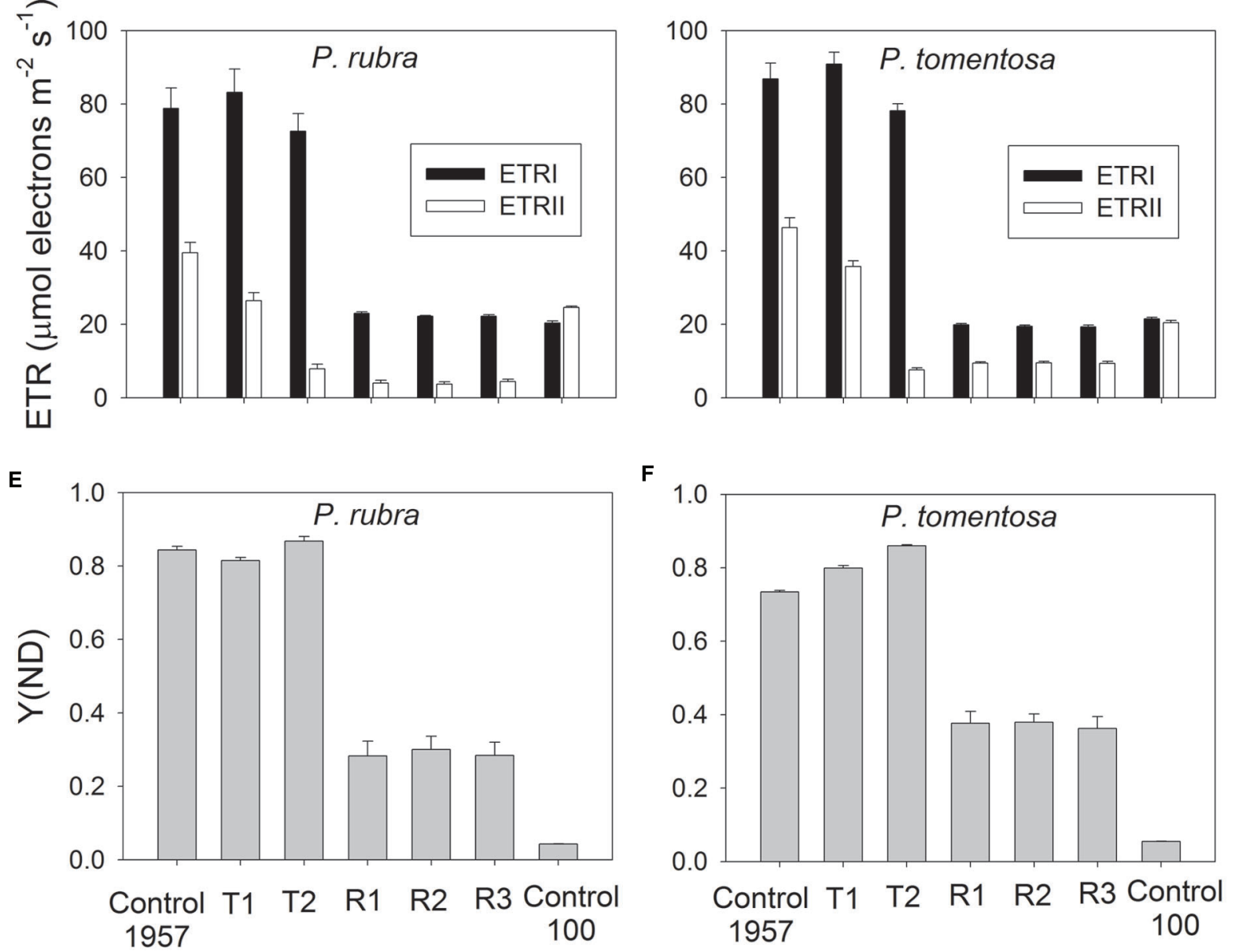

FIGURE 4 | Changes in Fm (A), Pm (B), ETR (C,D), and Y(ND) (E,F) in Psychotria rubra and Pometia tomentosa during treatment at $25^{\circ} \mathrm{C}$ and $2000 \mu \mathrm{mol}$ photons $\mathbf{m}^{-2} \mathbf{s}^{-1}$ and subsequent recovery at $100 \mu \mathrm{mol}$ photons $\mathbf{m}^{-2} \mathbf{s}^{-1}$. T1 and T2 represent the data after high light treatment for 1 and $2 \mathrm{~h}$, respectively. R1, R2, and R3 represent the data after recovery at low light for 1, 2, and $3 \mathrm{~h}$, respectively. Control 1957 and Control 100 represent the data measured at 1957 and $100 \mu \mathrm{mol}$ photons $\mathrm{m}^{-2} \mathrm{~s}^{-1}$ before treatment, respectively. The means \pm SE were calculated from six independent plants. Asterisks indicate significant differences between Psychotria rubra and Pometia tomentosa. 


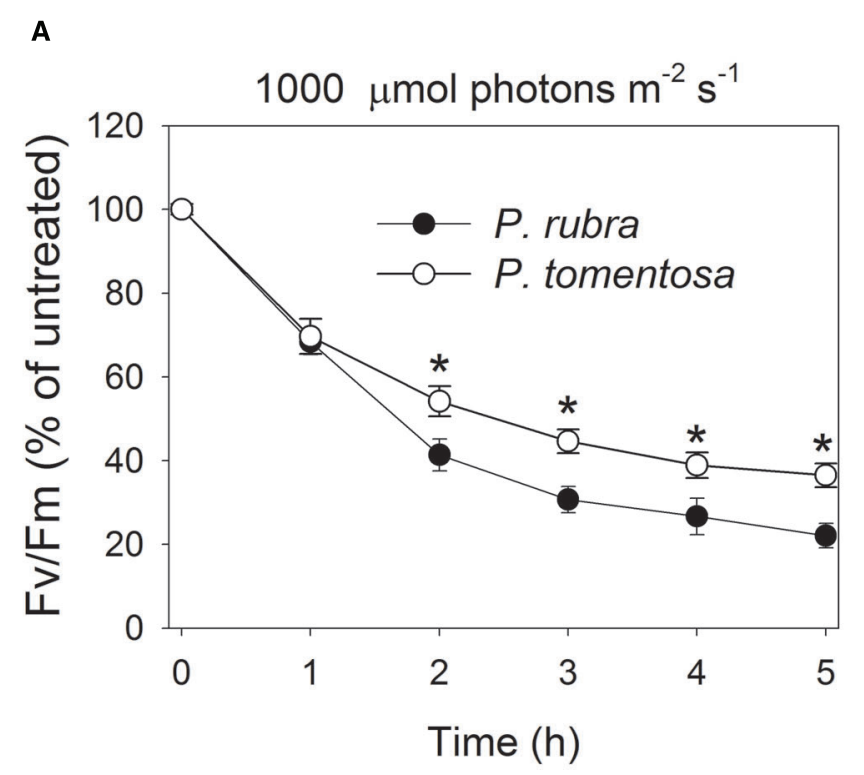

PPFD

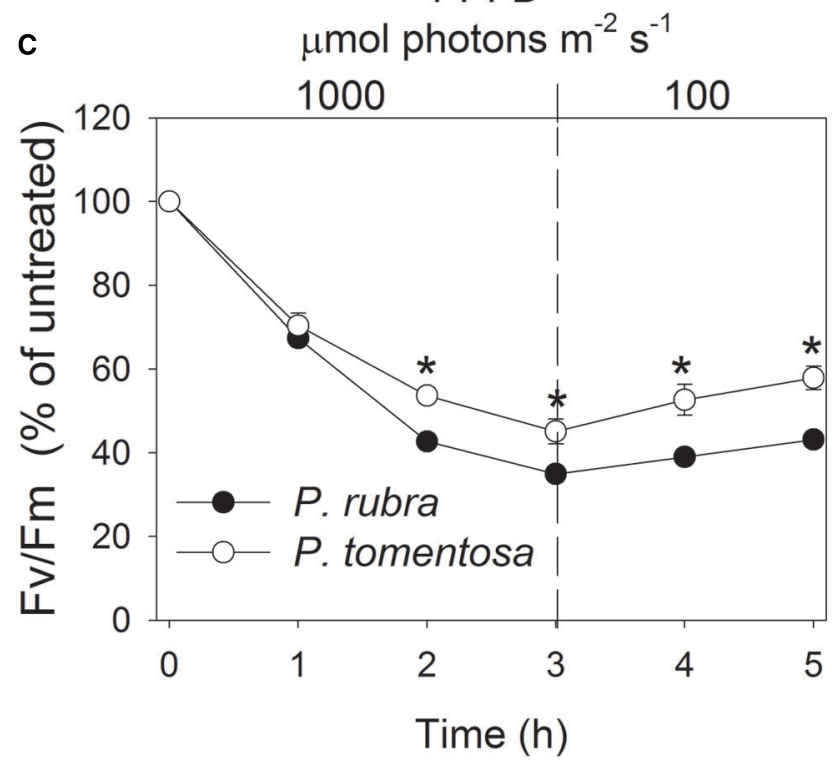

B

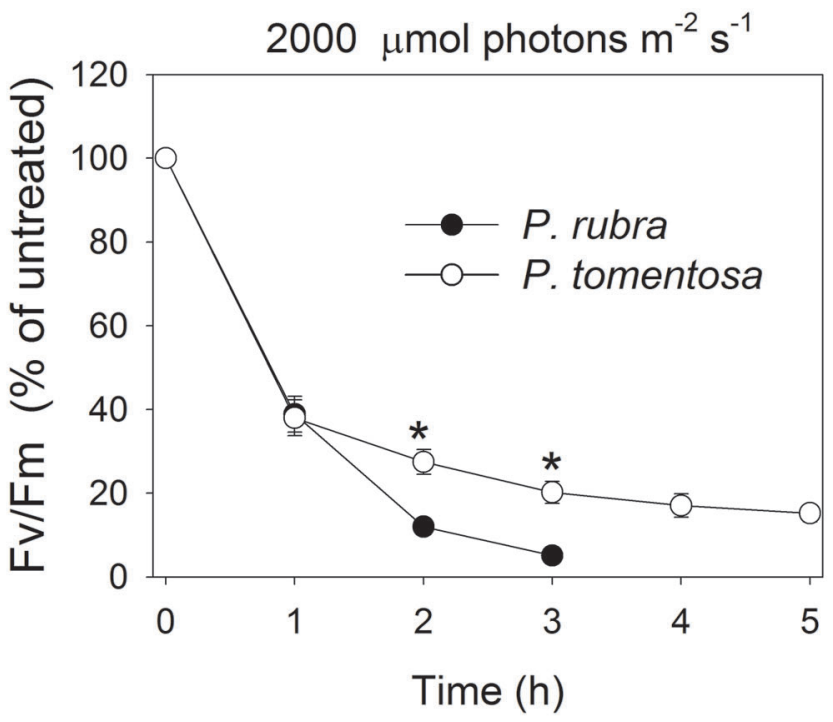

PPFD
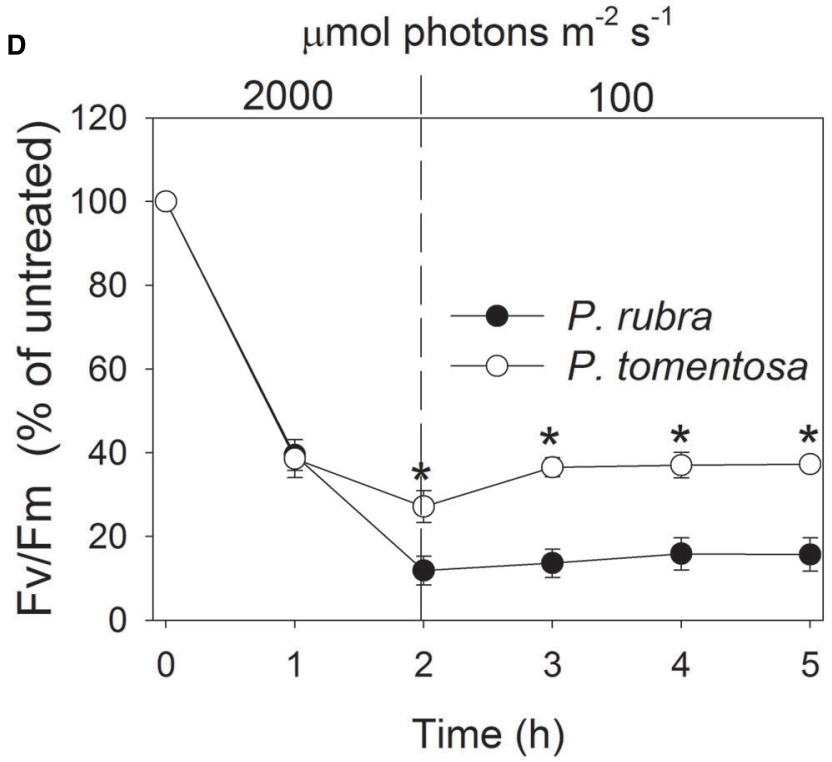

FIGURE 5 | Changes in $\boldsymbol{F}_{v} / \boldsymbol{F}_{m}$ in Psychotria rubra and Pometia tomentosa during treatments at $25^{\circ} \mathrm{C}$ associated with high light intensities of 1000 (A) and 2000 (B) $\mu \mathrm{mol}$ photons $\mathbf{m}^{-\mathbf{2}} \mathbf{s}^{-1}$ and subsequent recovery at $\mathbf{1 0 0} \mu \mathbf{m o l}$ photons $\mathbf{m}^{-\mathbf{2}} \mathbf{s}^{-\mathbf{1}}$ (C,D). The means $\pm S E$ were calculated from six independent plants. Asterisks indicate significant differences between Psychotria rubra and Pometia tomentosa.

(Figures 3E,F and 4E,F). This result indicated that CEF was also highly activated during recovery at low light in both species. The decline in ETRII and activation of CEF during recovery induced the increase in $\mathrm{Y}(\mathrm{ND})$.

During the photoinhibitory treatment at 1000 and $2000 \mu \mathrm{mol}$ photons $\mathrm{m}^{-2} \mathrm{~s}^{-1}, F_{v} / F_{m}$ gradually decreased in both species (Figures 5A,B). After treatment for $2 \mathrm{~h}$ and more time, the decrease in $F_{v} / F_{m}$ was larger in $P$. rubra than $P$. tomentosa. Interestingly, $F_{v} / F_{m}$ decreased to $5 \%$ of the original value in $P$. rubra after treatment at $2000 \mu \mathrm{mol}$ photons $\mathrm{m}^{-2} \mathrm{~s}^{-1}$ for $3 \mathrm{~h}$. These results indicated that high light induced stronger PSII photoinhibition in P. rubra. After exposure to $1000 \mu$ mol photons $\mathrm{m}^{-2} \mathrm{~s}^{-1}$ for $3 \mathrm{~h}, F_{v} / F_{m}$ gradually increased during recovery at $100 \mu \mathrm{mol}$ photons $\mathrm{m}^{-2} \mathrm{~s}^{-1}$ in both species (Figure 5C). However, $F_{v} / F_{m}$ hardly increased during recovery in $P$. rubra following treatment at $2000 \mu \mathrm{mol}$ photons $\mathrm{m}^{-2} \mathrm{~s}^{-1}$ for $2 \mathrm{~h}$ (Figure 5D).

To further confirm the susceptibility of PSI to high light in shade-established species, mature leaves of another shadeestablished species Pittosporopsis kerrii (Icacinaceae) were treated at high light. After exposure to $2000 \mu \mathrm{mol}$ photons $\mathrm{m}^{-2} \mathrm{~s}^{-1}$ for $4 \mathrm{~h}, F_{m}$ and $F_{v} / F_{m}$ largely decreased as expectedly. Meanwhile, $P_{m}$ decreased significantly by $29 \%$ (Figure 6). These results suggested 


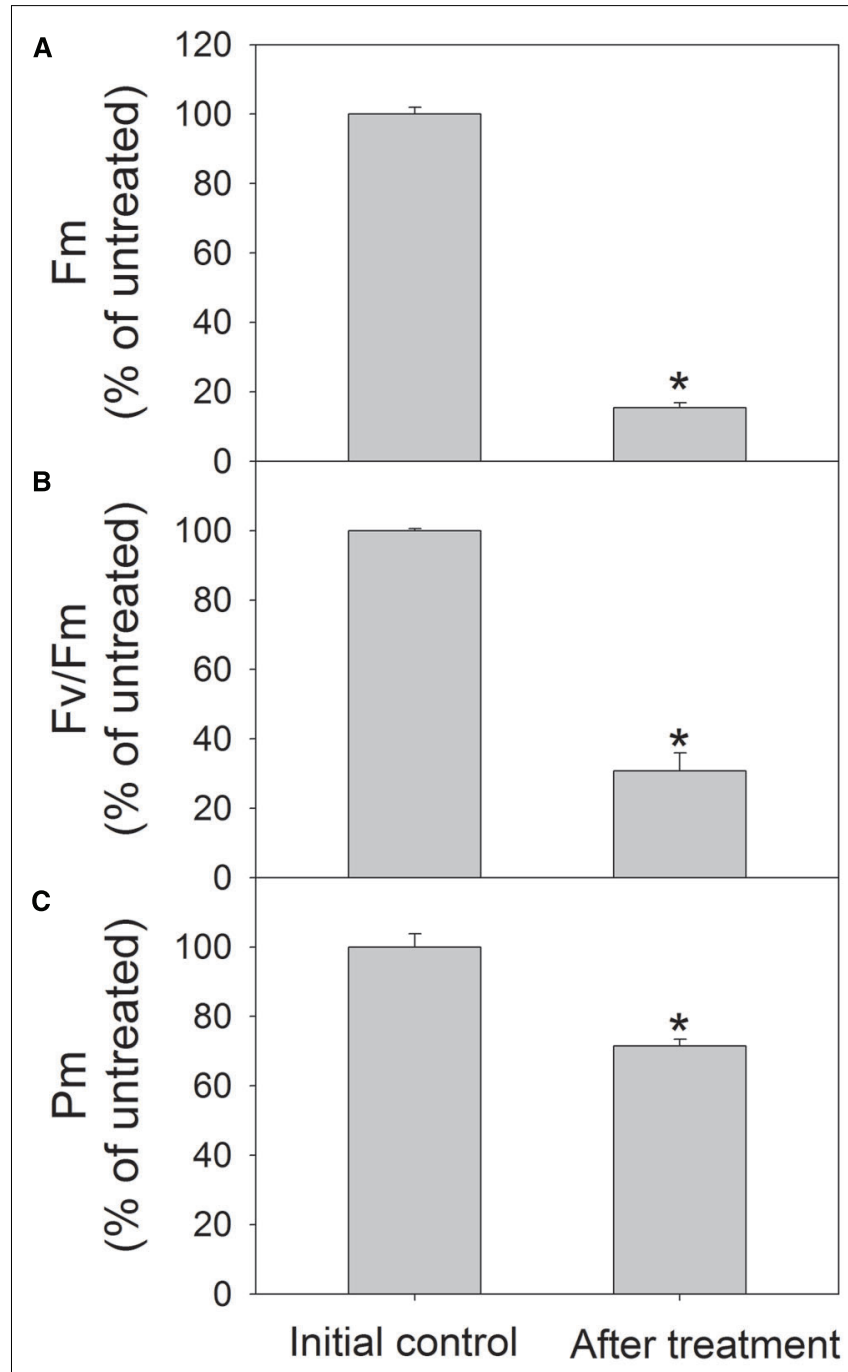

FIGURE 6 | Changes in $\boldsymbol{F}_{m}(\mathrm{~A}), \boldsymbol{F}_{v} / \boldsymbol{F}_{m}(\mathrm{~B})$, and $\boldsymbol{P}_{m}(\mathrm{C})$ in Pittosporopsis kerrii after exposure to $2000 \mu \mathrm{mol}$ photons $\mathrm{m}^{-2} \mathrm{~s}^{-1}$ for $\mathbf{4} \mathrm{h}$. The means \pm SE were calculated from six independent plants. Asterisks indicate significant differences between initial control and after treatment.

that PSI activity was susceptible to high light not only in P. rubra, but also in another shade-established species $P$. kerrii.

\section{Discussion}

It has been often considered that high light induces selective photodamage to PSII in nature, excluding chilling stress. However, the response of PSI to high light for shade-established tree species in unclear. Here we provide evidence that the shadeestablished species $P$. rubra is incapable of protecting PSI under high light. In addition, another shade-established species $P$. kerrii showed significantly PSI photoinhibition after exposure to high light. These results suggested that PSI photoinhibition is another important photosynthetic mechanism underlying the sensitivity of shade-established species to high light.

In a previous study, PSI activity remaining unaffected in tropical shade leaves after exposure to $1800 \mu \mathrm{mol}$ photons $\mathrm{m}^{-2} \mathrm{~s}^{-1}$ for $75 \mathrm{~min}$ (Barth et al., 2001). In our present study, PSI activity also changed little after exposure to 1000 or $2000 \mu \mathrm{mol}$ photons $\mathrm{m}^{-2} \mathrm{~s}^{-1}$ for $2 \mathrm{~h}$ in shade leaves of the sun-established species $P$. tomentosa (Figures 2B,D). In sharp contrast to $P$. tomentosa, PSI activity in the shade-established species $P$. rubra decreased to $60 \%$ of the original value after exposure to $2000 \mu \mathrm{mol}$ photons $\mathrm{m}^{-2} \mathrm{~s}^{-1}$ for $2 \mathrm{~h}$ (Figure 2D). These results indicate that the response of PSI activity to high light in shade leaves is dependent on the plant successional trait.

Photosystem I photoinhibition is mainly induced by the deleterious effect of hydroxyl radicals. Excess electrons transported from PSII to the acceptor side of PSI result in the formation of superoxide anion radicals as well as in the reduction of iron-sulfur centers in PSI (Sonoike et al., 1997; Sonoike, 2011). The dismutation of superoxide anion radicals produces hydroxyl peroxide, which reacts with reduced ironsulfur centers to form hydroxyl radicals that immediately destroy the iron-sulfur centers (Sonoike, 2006). The pgr5-mutants of Arabidopsis thaliana display photoinhibition of PSI under high light due to excess electrons from PSII to PSI and over-reduction of PSI acceptor side. In the present study, P. rubra showed high levels of P700 oxidation ratio during high light treatment. Thus, photoinhibition of PSI under high light in P. rubra was mainly caused by the excess electron transfer from PSII to PSI, but not correlated to over-reduction of PSI acceptor side. During exposure to $2000 \mu \mathrm{mol}$ photons $\mathrm{m}^{-2} \mathrm{~s}^{-1}$, PSI photoinhibition in $P$. rubra mainly occurred in the initial course of $2 \mathrm{~h}$ and longer treatment did not enhance PSI photodamage. P. rubra showed significant active electron flow from PSII to PSI (67\% of the original value) after exposure to $2000 \mu \mathrm{mol}$ photons $\mathrm{m}^{-2} \mathrm{~s}^{-1}$ for $1 \mathrm{~h}$ (Figure 4C). However, after $2 \mathrm{~h}$ of treatment at this high light, ETRII decreased to $20 \%$ of the original value (Figure 4C). These results indicated that, in the initial stage of exposure to $2000 \mu \mathrm{mol}$ photons $\mathrm{m}^{-2} \mathrm{~s}^{-1}$, the active electron flow from PSII to PSI induced the accumulation of hydroxyl radicals in the acceptor side and subsequently led to photodamage to PSI in $P$. rubra. Although the sun-established species $P$. tomentosa showed high levels of electron transfer from PSII to PSI during the initial treatment at $2000 \mu \mathrm{mol}$ photons $\mathrm{m}^{-2} \mathrm{~s}^{-1}$, PSI activity was maintained stable. Therefore, $P$. tomentosa maybe had higher ability to scavenge reactive oxygen species. Alternatively, the sensitivity of PSI to reactive oxygen species differed between shade- and sun-established species. In the near future, it is necessary to study the molecular mechanism underlying why PSI is sensitive to high light in leaves of the shade-established species P. rubra.

It is assumed that PSI gets damaged only when electron flow from PSII exceeds the capacity of PSI electron acceptors to cope with the electrons (Tikkanen and Aro, 2014). When illuminated at low light, PSI activity changed little in both the wild type and pgr5 mutants of Arabidopsis thaliana. However, the pgr5 mutants showed large decrease in PSI activity when exposed to high light for several hours (Munekage et al., 2002; Tikkanen et al., 2014). For the shade-established species P. rubra, PSI activity changed little after exposure to $100 \mu \mathrm{mol}$ photons $\mathrm{m}^{-2} \mathrm{~s}^{-1}$ for $5 \mathrm{~h}$ (data not shown). The significant PSI photoinhibition in the initial $2 \mathrm{~h}$ of high light treatment suggested that electron flow from PSII 
to PSI largely exceed the capacity of PSI electron acceptors in P. rubra. After $2 \mathrm{~h}$ exposure to $2000 \mu \mathrm{mol}$ photons $\mathrm{m}^{-2} \mathrm{~s}^{-1}$, electron flow from PSII to PSI largely declined. Subsequently, PSI activity was maintained stable during further high light treatment. The PSI activity was protected against further photodamage in pgr5 mutants of Arabidopsis thaliana upon moderate PSII photoinhibition, due to the depression of electron flow from PSII to PSI and the increase in P700 oxidation ratio (Tikkanen et al., 2014). After exposure to $2000 \mu \mathrm{mol}$ photons $\mathrm{m}^{-2} \mathrm{~s}^{-1}$ for $2 \mathrm{~h}$, $F_{m}$ decreased by approximately $85 \%$ in P. rubra (Figure 4A), which was accompanied with a large decrease in ETRII and no further photodamage of PSI (Figure 3C). Taking together, these results indicated that severe PSII photoinhibition restricts electron transfer from PSII to PSI and then alleviated PSI photodamage under high light in P. rubra.

On condition of excess light, CEF is activated to protect PSI and PSII against photoinhibition (Munekage et al., 2002; Takahashi et al., 2009; Tikkanen et al., 2014). CEF not only increases the P700 oxidation ratio (Munekage et al., 2002, 2004; Suorsa et al., 2012; Tikkanen et al., 2014) but also controls electron transfer from PSII to PSI via Cyt b6f complex (Tikkanen and Aro, 2014). At a normal growth temperature of $25^{\circ} \mathrm{C}$, it has been believed that wild-type plants are capable of protecting PSI under high light (Munekage et al., 2002, 2004; Suorsa et al., 2012; Tikkanen et al., 2014; Huang et al., 2015). However, our present study indicated that the shade-established species P. rubra was incapable of protecting PSI under high light, although it showed highly activation of CEF under high light. The pgr5-mutans showed PSI photoinhibition under high light mainly due to low P700 oxidation ratio. Surprisingly, photoinhibition of PSI under high light in P. rubra was accompanied with high levels of P700 oxidation ratio. Therefore, the mechanism of PSI photoinhibition probably differed between $P$. rubra and Arabidopsis thaliana, and CEF is unlikely to play a major role in photoprotection for PSI in P. rubra.

\section{References}

Allakhverdiev, S. I., and Murata, N. (2004). Environmental stress inhibits the synthesis de novo of proteins involved in the photodamage-repair cycle of photosystem II in Synechocystis sp. PCC 6803. Biochimi. Biophys. Acta 1657, 23-32. doi: 10.1016/j.bbabio.2004.03.003

Aro, E. M., Virgin, I., and Andersson, B. (1993a). Photoinhibition of photosystem II. Inactivation, protein damage and turnover. Biochim. Biophys. Acta 1143, 113-134. doi: 10.1016/0005-2728(93)90134-2

Aro, E. M., McCaffery, S., and Anderson, J. (1993b). Photoinhibition and D1 protein degradation in peas acclimated to different growth irradiances. Plant Physiol. 103, 835-843.

Barber, J., and Andersson, B. (1992). Too much of a good thing: light can be bad for photosynthesis. Trends Biochem. Sci. 17, 61-66. doi: 10.1016/09680004(92)90503-2

Barth, C., and Krause, G. H. (1999). Inhibition of photosystem I and II in chillingsensitive and chilling-tolerant plants under light and low-temperature stress. $Z$. Naturforsch. 54c, 645-657. doi: 10.1515/znc-1999-9-1006

Barth, C., Krause, G. H., and Winter, K. (2001). Responses of photosystem I compared with photosystem II to high-light stress in tropical shade and sun leaves. Plant Cell Environ. 24, 163-176. doi: 10.1111/j.1365-3040.2001.00673.x

Genty, B., Briantais, J. M., and Baker, N. R. (1989). The relationship between the quantum yield of photosynthetic electron transport and quenching of chlorophyll fluorescence. Biochim. Biophys. Acta 990, 87-92. doi: 10.1016/S0304-4165(89)80016-9
Surprisingly, PSI activity showed slightly decrease in both species during recovery at a low light of $100 \mu \mathrm{mol}$ photons $\mathrm{m}^{-2} \mathrm{~s}^{-1}$. As reported previously, light harvesting complex I proteins have a slow turnover (Kudoh and Sonoike, 2002; Zhang and Scheller, 2004). Once PSI photoinhibition happened, the photodamaged PSI complex is completely degraded (Zhang and Scheller, 2004). After $8 \mathrm{~h}$ recovery at low light and $20^{\circ} \mathrm{C}$, PSI activity recovered very slowly, and the amount of PSI on a leaf area basis remained low even after recovery for 1 week (Zhang and Scheller, 2004). Therefore, the little recovery of PSI activity in P. rubra and P. tomentosa may be as a result of the slow turnover.

\section{Conclusion}

Our results indicated that the shade-established tree species Psychotria rubra was incapable of protecting PSI under high light. Furthermore, highly activation of CEF could not prevent PSI against photoinhibition under high light in $P$. rubra. The extent of PSI photoinhibition under high light in $P$. rubra was mainly controlled by the electron transfer from PSII to PSI. When the canopy gaps are created, the strong sunlight can induce severe photoinhibition of both PSI and PSII in shade-established plant species. These findings suggest that photoinhibition of PSI may be an important mechanism explaining why shade-established species cannot survive under high light.

\section{Acknowledgments}

This work was supported by National Natural Science Foundation of China (grant 31300332), China Postdoctoral Science Foundation to WH (2014T70892), and an open fund from Key Laboratory of Tropical Forest Ecology, Xishuangbanna Tropical Botanical Garden, Chinese Academy of Sciences.

Havaux, M., and Davaud, A. (1994). Photoinhibition of photosynthesis in chilled potato leaves is not correlated with a loss of photosystem II activity-preferential inactivation of photosystem I. Photosynth. Res. 40, 75-92. doi: 10.1007/BF00019047

Huang, W., Fu, P.-L., Jiang, Y.-J., Zhang, J.-L., Zhang, S.-B., Hu, H., et al. (2013). Differences in the responses of photosystem I and photosystem II of three tree species Cleistanthus sumatranus, Celtis philippensis, and Pistacia weinmannifolia submitted to a prolonged drought in a tropical limestone forest. Tree Physiol. 33, 211-220. doi: 10.1093/treephys/tps132

Huang, W., Zhang, S.-B., and Cao, K.-F. (2010a). The different effects of chilling stress under moderate illumination on photosystem II compared with photosystem I and subsequent recovery in tropical tree species. Photosynth. Res. 103, 175-182. doi: 10.1007/s11120-010-9539-7

Huang, W., Zhang, S.-B., and Cao, K.-F. (2010b). Stimulation of cyclic electron flow during recovery after chilling-induced photoinhibition of PSII. Plant Cell Physiol. 51, 1922-1928. doi: 10.1093/pcp/pcq144

Huang, W., Zhang, S.-B., and Hu, H. (2015). Insusceptibility of oxygen-evolving complex to high light in Betula platyphylla. J. Plant Res. 128, 307-315. doi: 10.1007/s10265-014-0684-5

Hwang, H. J., Kim, J. H., Eu, Y. J., Moon, B. Y., Cho, S. H., and Lee, C. H. (2004). Photoinhibition of photosystem I is accelerated by dimethyldithiocarbamate, an inhibitor of superoxide dismutase, during light-chilling of spinach leaves. $J$. Photochem. Photobiol. B Biol. 73, 79-85. doi: 10.1016/j.jphotobiol.2003.09.008

Kim, S. J., Lee, C. H., Hope, A. B., and Chow, W. S. (2001). Inhibition of photosystem I and II and enhanced back flow of photosystem I electrons in cucumber leaf 
discs chilled in the light. Plant Cell Physiol. 42, 842-848. doi: 10.1093/pcp/ pce109

Kitao, M., Lei, T. T., Koike, T., Tobita, H., and Muruyama, Y. (2000). Susceptibility to photoinhibition of three deciduous broadleaf tree species with different successional traits raised under various light regimes. Plant Cell Environ. 23, 81-89. doi: 10.1046/j.1365-3040.2000.00528.x

Kono, M., Noguchi, K., and Terashima, I. (2014). Roles of cyclic electron flow around PSI (CEF-PSI) and O2-dependent alternative pathways in regulation of the photosynthetic electron flow in short-term fluctuating light in Arabidopsis thaliana. Plant Cell Physiol. 55, 990-1004. doi: 10.1093/pcp/pcu033

Krause, G. H., Grube, E., Koroleva, O. Y., Barth, C., and Winter, K. (2004). Do mature shade leaves of tropical tree seedlings acclimate to high sunlight and UV radiation? Funct. Plant Biol. 31, 743-756. doi: 10.1071/FP03239

Kudoh, H., and Sonoike, K. (2002). Irreversible damage to photosystem I by chilling in the light: cause of the degradation of chlorophyll after returning to normal growth temperature. Planta 215, 541-548. doi: 10.1007/s00425-002-0790-9

Munekage, Y., Hashimoto, M., Miyake, C., Tomizawa, K. I., Endo, T., Tasaka, M., et al. (2004). Cyclic electron flow around photosystem I is essential for photosynthesis. Nature 429, 579-582. doi: 10.1038/nature02598

Munekage, Y., Hojo, M., Meurer, J., Endo, T., Tasaka, M., and Shikanai, T. (2002). PGR5 is involved in cyclic electron flow around photosystem I and is essential for photoprotection in Arabidopsis. Cell 110, 361-371. doi: 10.1016/S0092$8674(02) 00867-\mathrm{X}$

Murata, N., Takahashi, S., Nishiyama, Y., and Allakhverdiev, S. I. (2007). Photoinhibition of photosystem II under environmental stress. Biochim. Biophys. Acta 1767, 414-421. doi: 10.1016/j.bbabio.2006.11.019

Nishiyama, Y., Allakhverdiev, S. I., Yamamoto, H., Hayashi, H., and Murata, N. (2004) Singlet oxygen inhibits the repair of photosystem II by suppressing the translation elongation of the D1 protein in Synechocystis sp. PCC 6803. Biochemistry 43, 11321-11330.

Nishiyama, Y., Allakhverdiev, S. I., and Murata, N. (2005). Inhibition of the repair of photosystem II by oxidative stress in cyanobacteria. Photosynth. Res. 84, 1-7. doi: $10.1007 / \mathrm{s} 11120-004-6434-0$

Nishiyama, Y., Allakhverdiev, S. I., and Murata, N. (2006). A new paradigm for the action of reactive oxygen species in the photoinhibition of photosystem II. Biochim. Biophys. Acta 1757, 742-749. doi: 10.1016/j.bbabio.2006.05.013

Nishiyama, Y., Allakhverdiev, S. I., and Murata N. (2011). Protein synthesis is the primary target of reactive oxygen species in the photoinhibition of photosystem II. Physiol. Plant. 142, 35-46. doi: 10.1111/j.1399-3054.2011.01457.x

Nishiyama, Y., Yamamoto, H., Allakhverdiev, S. I., Inaba, M., Yokota, A., and Murata, N. (2001). Oxidative stress inhibits the repair of photodamage to the photosynthetic machinery. EMBO J. 20, 5587-5594. doi: $10.1093 /$ emboj/20.20.5587

Nuijs, A. M., Shuvalov, A., van Gorkom, H. J., Plijter, J. J., and Duysens, L. N. M. (1986). Picosecond absorbance difference spectroscopy on the primary reactions and the antenna-excited states in photosystem I particles. Biochim. Biophys. Acta 850, 310-318. doi: 10.1016/0005-2728(86)90186-6

Peng, L., and Shikanai, T. (2011). Supercomplex formation with photosystem I is required for the stabilization of the chloroplast NADH dehydrogenaselike complex in Arabidopsis. Plant Physiol. 155, 1629-1639. doi: $10.1104 /$ pp.110.171264

Powles, S. B. (1984). Photoinhibition of photosynthesis induced by visible light. Annu. Rev. Plant Physiol. 35, 15-44. doi: 10.1146/annurev.pp.35.060184.000311
Sonoike, K. (1995). Selective photoinhibition of photosystem I in isolated thylakoid membranes from cucumber and spinach. Plant Cell Physiol. 36, 825-830.

Sonoike, K. (2006). "Photoinhibition and protection of photosystem I," In Photosystem I: the Light-driven Plastocyanin: Ferredoxin Oxidoreductase, Series Advances in Photosynthesis and Respiration, ed. J. H Golbeck (Dordrecht: Springer), 657-668. doi: 10.1007/978-1-4020-4256-0_38

Sonoike, K. (2011). Photoinhibition of photosystem I. Physiol. Plant. 142, 56-64. doi: $10.1111 / j .1399-3054.2010 .01437 . x$

Sonoike, K., Kamo, M., Hihara, Y., Hiyama, T., and Enami, I. (1997). The mechanism of the degradation of $\mathrm{psaB}$ gene product, one of the photosynthetic reaction center subunits of photosystem I, upon photoinhibition. Photosynth. Res. 53, 55-63. doi: 10.1023/A:1005852330671

Suorsa, M., Jarvi, S., Grieco, M., Nurmi, M., Pietrzykowska, M., Rantala, M., et al. (2012). PROTON GRADIENT REGULATION5 is essential for proper acclimation of Arabidopsis photosystem I to naturally and artificially fluctuating light conditions. Plant Cell 24, 2934-2948. doi: 10.1105/tpc.112.097162

Takahashi, S., and Badger, M. R. (2011). Photoprotection in plants: a new light on photosystem II damage. Trend Plant Sci. 16, 53-60. doi: 10.1016/j.tplants.2010.10.001

Takahashi, S., Milward, S. E., Fan, D. Y., Chow, W. S., and Badger, M. R. (2009). How does cyclic electron flow alleviate photoinhibition in Arabidopsis? Plant Physiol. 149, 1560-1567. doi: 10.1104/pp.108.134122

Terashima, I., Funayama, S., and Sonoike, K. (1994). The site of photoinhibition in leaves of Cucumis sativus L. at low temperatures is photosystem I, not photosystem II. Planta 193, 300-306. doi: 10.1007/BF00192544

Tikkanen, M., Grieco, M., Kangasjarvi, S., and Aro, E. M. (2010). Thylakoid protein phosphorylation in higher plant chloroplasts optimizes electron transfer under fluctuating light. Plant Physiol. 152, 723-735. doi: 10.1104/pp.109.150250

Tikkanen, M., and Aro, E. M. (2014). Integrative regulatory network of plant thylakoid energy transduction. Trends. Plant Sci. 19, 10-17. doi: 10.1016/j.tplants.2013.09.003

Tikkanen, M., Mekala, N. R., and Aro, E. M. (2014). Photosystem II photoinhibitionrepair cycle protects Photosystem I from irreversible damage. Biochim. Biophys. Acta 1837, 210-215. doi: 10.1016/j.bbabio.2013.10.001

Yamori, W., Sakata, N., Suzuki, Y., Shikanai, T., and Maniko, A. (2011). Cyclic electron flow around photosystem I via chloroplast NAD(P)H dehydrogenase (NDH) complex performs a significant physiological role during photosynthesis and plant growth at low temperature in rice. Plant J. 68, 966-976. doi: 10.1111/j.1365-313X.2011.04747.x

Zhang, S.-P., and Scheller, H. V. (2004). Photoinhibition of photosystem I at chilling temperature and subsequent recovery in Arabidopsis. Plant Cell Physiol. 45, 1595-1602. doi: 10.1093/pcp/pch180

Conflict of Interest Statement: The authors declare that the research was conducted in the absence of any commercial or financial relationships that could be construed as a potential conflict of interest.

Copyright () 2015 Huang, Zhang, Zhang and Hu. This is an open-access article distributed under the terms of the Creative Commons Attribution License (CC BY). The use, distribution or reproduction in other forums is permitted, provided the original author(s) or licensor are credited and that the original publication in this journal is cited, in accordance with accepted academic practice. No use, distribution or reproduction is permitted which does not comply with these terms. 